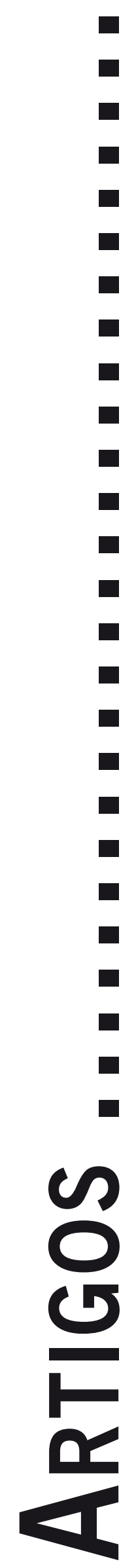




\title{
REFLEXÕES SOBRE A AFINIDADE DE JUNG COM A FENOMENOLOGIA
}

\author{
Considerations on the Kinship of Jung and Phenomenology
}

Reflexiones Sobre la Afinidad de Jung con la Fenomenología

Andrea de Alvarenga Lima

Jean Carlo Kurpel Diogo

\begin{abstract}
Resumo: Tendo em vista a posição de Jung no meio acadêmico nacional, o presente trabalho se propõe a uma análise epistemológica a respeito da relação entre Jung e a Fenomenologia. Primeiramente, revisou-se o desenvolvimento histórico do conceito de Fenomenología, visando delinear o sentido em que Husserl, fundador da Fenomenologia enquanto movimento filosófico se apropria do termo. Posteriormente, buscou-se compreender, na obra de Jung, o sentido no qual empregava o termo e a sua relação pessoal com o movimento fenomenológico. Concluiu-se que a aproximação entre Jung e a Fenomenología de Husserl se estabelece, não em termos de radicais filosóficos, mas, a partir da proximidade da postura que ambos assumem em seus métodos.
\end{abstract}

Palavras-chave: Fenomenologia; Jung; Psicologia Analítica.

\begin{abstract}
Considering Jung's position in the national academic context, the present paper presents an epistemological analysis of the relationship between Jung and Phenomenology. First, the historical development of the concept of Phenomenology was revised, in order to outline the meaning in which Husserl, founder of Phenomenology as a philosophical movement, applies the term. After that, it tries to understand in Jung's work how he used the term and how he personally related to the phenomenological movement. In conclusion, it suggests that the resemblance between Jung and Husserl's Phenomenology is established not in terms of philosophical radicals but from a similar methodological attitude.
\end{abstract}

Keywords: Phenomenology; Jung; Analytical Psychology.

Resumen: En vista de la posición de Jung en la académica nacional, el presente trabajo se propone a un análisis epistemológico de la aproximación entre la teoría junguiana y la propuesta fenomenológica husserliana. Primeramente, se hace una revisión del desarrollo histórico del concepto de Fenomenología, de modo que se pudiera delinear el sentido en el cual Husserl, fundador de la Fenomenología como un movimiento filosófico, apropiase del término. Después, se busca compreender en la obra de Jung el sentido en el cual el autor utilizase del término y su relación personal con el movimiento fenomenológico. En conclusión, la aproximación entre Jung y la Fenomenología de Husserl se establece no en los términos de radicales filosóficos, pero si por la proximidad de la postura que los dos asumen em su método.

Palabras-clave: Fenomenología; Jung; Psicología Analítica.

\section{A Posição de Jung no Meio Acadêmico Nacional}

As contribuições do psiquiatra suíço Carl Gustav Jung (1875-1961) ao campo da Psicologia são extensas e profundas. Suas propostas teóricas e clínicas embasam a prática de um numeroso grupo de psicólogos e psicoterapeutas. Sua posição, enquanto pensador, no entanto, nunca foi bem estabelecida nos meios acadêmicos. Giegerich (2004), um dos mais respeitados autores pós-junguianos, assinala que o trabalho de Jung, diferentemente da obra freudiana, não atraiu e nem inspirou grandes mentes, pensadores, escritores e artistas.

Pesquisador original e criativo, Jung é autor de uma vasta obra, cujo interesse ultrapassa a Psicologia, ecoando por áreas afins como a Teologia, a Antropologia e a Etnologia, além da História Comparada das Religiões. Para seus defensores mais acirrados, o descaso por sua obra deveu-se ao fato de que "Jung estava a tal ponto à frente da sua época que as pessoas somente aos poucos começam a alcançar suas descobertas" (Von Franz, 1975/1992, p. 11).

Giegerich (2004), porém, é mais crítico, ao admitir, na questão da ausência de pensadores junguianos nas universidades, tanto o caráter fundamentalmente subjetivista e amadorístico de muitas publicações "pop-junguianas", quanto a forma pretensiosa no uso de símbolos e mitos e expressões tais como: "o sagrado" e o "numinoso", no jargão junguiano. A existência desses "traços sombrios" pode ser compreendida, segundo o autor, na esteira de inconsistências do próprio pensamento de Jung.

No cenário nacional, no entanto, o quadro está se modificando. Respondendo a um crescente interesse, por parte dos alunos, na Psicologia Analítica, observa-se uma presença mais forte dos estudos junguianos nos cursos 
de graduação. Na cidade de Curitiba-PR, por exemplo, os principais cursos de Psicologia oferecem a possibilidade de uma introdução à clínica de orientação junguiana. Nacionalmente, além de vários cursos de pós-graduação latu sensu, já existe, desde 2006, um primeiro programa de mestrado em Psicologia Clínica em estudos junguianos na PUC-SP. É importante mencionar que, em muitas instituições acadêmicas, a Psicologia Analítica é apresentada juntamente com as psicologias de abordagem fenomenológica.

No âmbito institucional clínico, existem duas organizações no Brasil com filiação plena à International Association for Analytical Psycology - IAAP (Zurique), que promovem programas de fundamentação teórica e prática para a formação de analistas na perspectiva junguiana. A Associação Junguiana do Brasil, $A J B$, cujas atividades formativas encontram-se distribuídas entre seis Institutos regionais (Paraná, São Paulo, Rio de Janeiro, Minas Gerais, Rio Grande do Sul e Campinas); e a Sociedade Brasileira de Psicologia Analítica, SBPA, que atua por intermédio do Instituto de Formação C. G. Jung de São Paulo e da Associada do Rio de Janeiro.

Jung foi um autor complexo e multifacetado, cujo texto apresenta diferentes níveis de discurso - psicológico, filosófico, científico, mitológico, teológico. Sua obra se formou, organicamente, em torno de temas de interesse que foram reformulados, ampliados e refinados ao longo de sua vida. Seu pensamento, ainda que sempre relacionado a uma disciplina particular, a Psicologia, e a um assunto específico, a psique humana, não tinha um objetivo único e inequívoco e era aberto ao insight e à experiência empírica.

No entanto, na tentativa de destilar uma doutrina ou simplesmente caracterizar de forma sintética a obra junguiana, muitas das interpretações têm priorizado certos aspectos em detrimento de outros, o que acarretou reducionismos e rotulações. Jung foi considerado místico, antirracionalista, antissemita, cristão, gnóstico, profeta, cientista, ocultista, poeta, curador. (Clarke, 1992/1993; Shamdasani, 2003/2006).

Nesse sentido, não causa surpresa a pluralidade da disciplina que se formou a partir do trabalho de Jung.

Continua-se falando no singular da "psicologia analítica”. Dentro de uma perspectiva descritiva, seria mais preciso hoje, falar de um arquipélago de psicologias junguianas díspares, que basicamente pouco têm a ver umas com as outras ou, inclusive, até com Jung (Shamdasani, 2003/2006, p. 29).

Dentre as importantes reinterpretações da obra junguiana, encontra-se um importante grupo de autores que foram criativamente influenciados por discussões pautadas em filosofias fenomenológicas. Destacamse, dentre eles: James Hillman, Wolfgang Giegerich, Lopez-Predraza, Corbin, Patricia Berry, Thomas Moore,
Murray Stain, Robert Sardello, e Guggenbuhl-Craig, entre outros.

Hillman (1988/1992), por exemplo, tendo colaborado com professores de fenomenologia da Universidade de Dallas, na década de 80, delimitou a Psicologia Arquetípica referindo-se a uma psicologia que, baseada na teoria junguiana, se centra no conceito de arquétipo e foca seu interesse no fenômeno da imagem e na perspectiva imaginal. Em outras palavras, a Psicologia Arquetípica prioriza o que há de postura fenomenológica, na obra junguiana, abrindo mão de uma teoria psicodinâmica e de conceitos como self e individuação.

A leitura que Hillman faz, de Jung, dá um matiz ainda mais fenomenológico a uma obra que, como se verá a seguir, traz em si elementos de uma perspectiva fenomenológica. Faz-se necessário, portanto, delimitar, de uma maneira mais substancial, como e à qual fenomenologia o pensamento junguiano se vincula. O presente trabalho se coloca a serviço dessa exploração. Tal tarefa requer, entretanto, uma breve revisão do desenvolvimento histórico do conceito de fenomenologia.

\section{O Conceito de Fenomenologia Através dos Tempos}

Fenomenologia, em seu sentido etimológico, formase da conjunção entre as palavras gregas phainomenon (fenômeno, literalmente "aquilo que aparece") e logos (estudo, discurso). Com efeito, pode-se dizer que, a princípio, fenomenologia seria o estudo ou a ciência dos fenômenos.

O termo fenomenologia foi empregado em diferentes contextos e por diferentes pensadores ao longo da história da filosofia. Alguns autores, dentre outros, Dartigues (2008) e Bonaccini (2006), indicam que o termo foi utilizado, pela primeira vez, no ano de 1764, pelo matemático francês Johann Heinrich Lambert (1728-1777). Lambert referiu-se à fenomenologia como um estudo puramente descritivo daquilo que aparece, ou seja, a análise do fenômeno, tal qual este se apresenta à experiência humana, visando à distinção entre verdade e aparência.

Em 1781, o filósofo Immanuel Kant (1724-1804), "amante da metafísica", publicou sua Crítica da Razão Pura, a partir da qual dividia o conhecimento humano em sensível e intelectivo. Enquanto o conhecimento intelectivo está relacionado à lógica e ao julgamento, o conhecimento sensível, por sua vez está relacionado à estética e caracteriza-se como uma intuição, ou seja, um conhecimento imediato do mundo. Entretanto, aquilo que se apresenta à intuição não são os objetos em si, mas, as aparências deles. Kant usou o termo fenômeno para referir-se às aparências e númeno para referir-se às coisas em si (Reale \& Antiseri, 2005a).

Posteriormente, o filósofo Johann Gottlieb Fichte (1762-1814), discípulo de Kant, ainda que radicalizando o pensamento kantiano a um idealismo, continuou a 
referir-se aos fenômenos como aparências das coisas em si, mantendo a concepção de que as essências das coisas estariam para além de suas aparências, sendo, portanto, metafenomênicas (Reale \& Antiseri, 2005a).

Em 1807, Georg Wilhelm Friedrich Hegel (1770-1831), contemporâneo e estudioso de Fichte (idealismo) e de Schelling (romantismo), publicou o importante trabalho Fenomenologia do Espírito, no qual usou o termo para denominar sua filosofia que tinha o objetivo de "purificar a consciência fenomênica e de elevá-la mediatamente até o saber absoluto" (Reale \& Antiseri, 2005b, p. 110). Bello (2004) afirma que Hegel substituiu o termo eu pelo termo espírito e fundamentou toda a realidade histórica, natural, política e ética em uma racionalidade espiritual. A função da fenomenologia hegeliana seria, nesse sentido, a de superar a dicotomia entre sujeito e objeto, caracterizando-se como um caminho dialético de elevação do homem do fenômeno particular ("espírito finito", "eu empírico" e "consciência fenomênica”) ao fenômeno universal ("espírito infinito", "eu transcendental” e "saber absoluto”). “Aquilo que aparece” sempre será o espírito em suas diferentes formas. É nesse sentido que, em Hegel, a fenomenologia caracteriza-se como uma ciência do espírito.

Em contraponto ao idealismo hegeliano, o século XIX assistiu ao surgimento de outro sistema de pensamento, criado pelo filósofo francês August Comte (1798-1857): o Positivismo. Tal escola filosófica entendia que a ciência é o único caminho para se alcançar a verdade e que o conhecimento verdadeiro e positivo é aquele que é útil, experimentável e concreto.

A difusão do Positivismo produziu uma grande crise do saber. Essa crise, iniciada no final do século XIX, estendeu-se até meados do século XX, e atingiu a filosofia, as ciências naturais e, principalmente, as ciências humanas. De acordo com Merleau-Ponty (1958/1973), a crise das ciências foi marcada, na Europa, por uma ascensão do irracionalismo e, conseqüentemente, de ruptura com o Positivismo, que pouco tinha a dizer sobre os problemas humanos daquele momento histórico, a começar pela dicotomia entre o idealismo o realismo na filosofia.

Imerso nesse contexto, Husserl (1859-1938) aponta para a urgência de se repensar os fundamentos e a racionalidade das ciências humanas e escreve, no início do século XX, suas primeiras obras, propondo um recomeço radical na ordem do saber. Conforme Bello (2004), Husserl, matemático de formação, pretendia tornar a filosofia uma ciência da qual nada ficaria fora do campo de investigação. Em outras palavras, o propósito de Husserl era fundamentar cientificamente, a filosofia, transformando-a numa ciência rigorosa. Seu ponto de partida foi criticar as ciências positivistas, naturalistas e empíricas.

A discussão sobre o método das ciências humanas já estava presente nas obras de outros pensadores, tais como Dilthey (1833-1912), que critica a adoção do método das ciências da natureza nas ciências humanas. Afirmava que a natureza poderia ser acessada de forma indireta por meio de explicações sobre fatos e elementos, "mas que a vida psíquica é uma totalidade da qual temos compreensão intuitiva e imediata" (Forghieri, 1993, p. 14). O filósofo acreditava que era preciso voltar ao "sentimento de vida", esse, sim, seria o verdadeiro fundamento e método para a compreensão das ciências humanas. Dilthey propõe que as ciências sejam classificadas em naturwissenschaften (ciências da natureza) e geisteswissenchaften (ciências do espírito): o objeto das primeiras pode ser explicado, enquanto, o das últimas, deve ser compreendido.

Outro pensador que influenciou o trabalho de Husserl foi Franz Clemens Brentano (1838-1917). Ex-sacerdote austríaco, em polêmica com o idealismo pós-hegeliano, que reelaborou o conceito de intencionalidade dos fenômenos psíquicos a partir da "noção escolástica de um intentio animi, a inclinação da mente para um objeto" (Hamlyn, 1987/1990). Segundo ele, haveria uma divergência entre os fenômenos físicos e os psíquicos, já que estes possuiriam intencionalidade e "um modo de percepção original, imediato" (Forghieri, 1993, p. 14). Maciel (2007) afirma que, enquanto Wundt propunha uma psicologia experimental que se ocupa de conteúdos objetivos, Brentano, defendia uma psicologia empírica que se ocupasse dos atos mesmos da consciência.

A partir do conceito de intencionalidade de Brentano, Husserl contorna a dicotomia sujeito-objeto, que tinha como conseqüência limitações na compreensão das relações entre corpo e espírito, homem e mundo, real e ideal. Husserl postula que toda consciência é intencional, o que significa que não há uma consciência pura e separada do mundo. Toda consciência é uma consciência de alguma coisa, bem como, todo objeto somente pode ser definido a partir de sua relação com um sujeito (Dartigues, 2008). Brentano afirma que um objeto é sempre um fenômeno, algo que aparece para uma consciência, estando, inevitavelmente, relacionado a um sujeito e isento, assim, da objetividade e neutralidade pretendidas pelo positivismo.

Estabelece-se, portanto, uma nova relação entre sujeito e objeto. Uma conexão inseparável entre homem e mundo. Consciência e fenômeno não existem separados um do outro e as idéias só existem porque são idéias de alguma coisa. Os fenômenos do mundo doam-se à consciência e esta, por sua vez, sendo ativa e não meramente passiva, dá um sentido para os fenômenos que nela se constituem. Ao opor-se à concepção de consciência como entidade que contém representações de percepções, Husserl aproxima-se de Brentano no que este defendia uma análise psicológica dos atos mentais e não do conteúdo a que visam.

Husserl, enquanto matemático aberto à influência da Psicologia, postulava uma base psicológica para as operações aritméticas elementares. Em resposta às críticas da comunidade científica que apontavam essas operações como lógicas, Husserl retoma sua reflexão questionando- 
se a respeito das diferenças entre psique e pensamento. Para tanto, estabelece uma análise do processo de conhecimento que, ele próprio, define como fenomenológica (Bello, 2004). Sua formação em matemática apontava-lhe para a necessidade dessa análise ser, rigorosamente, metodológica. Merleau-Ponty (1945/1994) afirma que a fenomenologia só é acessível a um método fenomenológico, e existe, como movimento, antes mesmo de alcançar uma inteira consciência filosófica. O pensar fenomenológico é metodológico e não possui um fim em si mesmo, pois sua função é a de abrir as portas para uma nova compreensão do mundo.

O método fenomenológico caracteriza-se como um processo de, como o próprio Husserl o chamava, "retorno às coisas mesmas", de busca das essências dos fenômenos, que equivalem aos sentidos das experiências. $\mathrm{O}$ primeiro passo do método é a redução ao fenômeno, ou epoché, termo resgatado da filosofia medieval que significa um estado de repouso mental onde nada se nega e nada se afirma. Nesse estado, o sujeito prescinde de sua atitude natural e ingênua e coloca o mundo entre parênteses. "Isso não significa negar sua existência, mas metodicamente renunciar ao seu uso" (Zilles, 2007, p. 218). Assim, a questão não é abrir mão das certezas cotidianas. Abster-se delas é necessário para que apareçam claramente, visto que, por serem pressupostos de toda reflexão, passam despercebidas. Husserl prossegue-se para a redução eidética, ou intuição das essências, que procura captar o universalmente válido, aquilo que permanece para além das diferentes perspectivas pelas quais o mesmo fenômeno pode ser percebido. Voltar às coisas mesmas e construir conhecimento rigoroso a partir dos dados imediatos da consciência caracteriza o método fenomenológico com que Husserl respondeu à crise das ciências e ao psicologismo, ao historicismo e ao sociologismo que as impregnavam.

Essa breve exposição do percurso histórico do conceito de fenomenologia faz perceber que o termo, num primeiro momento, limitava-se a ser utilizado como um conceito alocado dentro de um sistema filosófico. A partir de Husserl, o termo fenomenologia passou a designar um movimento filosófico que deixou marcas significativas na maneira pela qual pensadores notáveis, como Heidegger e Sartre, construíram seus sistemas e que continua se desenvolvendo criativamente. Além disso, as repercussões da proposta fenomenológica não se limitaram ao campo das discussões filosóficas, pois, também assinalaram novos objetivos para as ciências humanas. Na Psicologia, em especial, a proposta husserliana de "busca das essências" ou "retorno às coisas mesmas" contribui para a construção de diferentes projetos, tais como a Gestalt-terapia, o Psicodrama e as terapias corporais.

Cabe agora estabelecer como Jung se posiciona em relação pensamento fenomenológico e a partir de quais aspectos de sua obra é possível delinear uma "fenomenologia junguiana”.

\section{A Fenomenologia de Jung}

Epistemologicamente, Jung é influenciado por variadas vertentes de pensamento. Seu trabalho se filia à psiquiatria dinâmica moderna, cujas raízes históricas remontam à medicina primitiva, perfaz uma trajetória até o pensamento científico que passa pelas práticas medievais de exorcismo, pelo magnetismo e pelo hipnotismo. Seus pressupostos filosóficos foram influenciados, em vários aspectos, pelo pensamento do filósofo Immanuel Kant, aproximando-se da linha de pensadores neokantianos, tais como Dilthey e Cassirer. Além disso, Jung demonstrou profunda afinidade com as tradições intelectuais do Romantismo e do Idealismo alemão. Leu, com entusiasmo, os poetas Goethe e Schiller e pensadores como Hegel, Schelling, Fichte, Shopenhouer, Von Hartmann e Nietzsche (Clarke, 1992/1993; Ellenberger, 1970).

Jung, em vários momentos, qualificou seu trabalho como de caráter fenomenológico. Em suas Obras Completas, o tema fenomenologia é discutido em, pelo menos, treze diferentes passagens. Na introdução ao livro Psicologia da Religião Ocidental e Oriental (1988), Jung afirma:

Embora me tenham chamado freqüentemente de filósofo, sou apenas um empírico e, como tal, me mantenho fiel ao ponto de vista fenomenológico. Mas não acho que infringimos os princípios do empirismo científico se, de vez em quando, fazemos reflexões que ultrapassam o simples acúmulo de classificação do material proporcionado pela experiência. Creio, de fato, que não há experiência possível sem uma consideração reflexiva, porque a "experiência" constitui um processo de assimilação, sem o qual não há compreensão alguma. Daqui se deduz que abordo os fatos psicológicos, não sob um ângulo filosófico, mas de um ponto de vista científico-natural. (...) me abstenho de qualquer abordagem metafísica ou filosófica. Não nego a validade de outras abordagens, mas não posso pretender a uma correta aplicação desses critérios (p. 1).

O autor mostra que sua fidelidade à perspectiva fenomenológica não expressava uma afinidade com as fenomenologias oriundas do pensamento husserliano, apenas que sua Psicologia era empírica no sentido de estar fundamentada mais na observação e experimentação daquilo que aparece, do que na teoria. Jung não nutria grande simpatia, nem se fazia muito estimado, em relação aos seus contemporâneos filósofos e pesquisadores da corrente fenomenológica. Husserl não é citado nem uma só vez nas Obras Completas. A respeito de outros autores da fenomenologia, em uma carta de 1939, Jung escreve:

O que Heidegger, Klages, Jaspers e outros disseram a esse respeito [discussão filosófica sobre psicoterapia] 
nunca me afetou profundamente, pois percebe-se logo nos escritores que eles nunca tiveram que lidar com os problemas práticos da psicoterapia. Todos têm uma impressionante facilidade verbal, o que lhes confere uma competência quase mágica. Se Klages tivesse que tratar em profundidade um único caso de neurose, jamais teria escrito o grosso volume sobre o espírito obnóxio. Do mesmo modo teria Heidegger perdido a vontade de dedicar-se a artifícios lingüísticos (2001, p. 283).

Em outro momento, coloca que Heidegger, um dos frutos da "perversão intelectual" alemã, procuraria "em vão esconder atrás de uma linguagem inchada" seus "preconceitos inconscientes e subjetivos".

O modus philosophandi de Heidegger é totalmente neurótico e baseia-se em última análise em sua excentricidade psíquica. Os seus afins mais próximos e mais remotos estão em manicômios, alguns como pacientes e outros como psiquiatras com ares filosóficos. Apesar de todas as falhas, o século XIX merece mais do que Heidegger como seu último representante (Jung, 2001, p. 336).

A antipatia é recíproca. Spiegelberg, um dos mais destacados estudiosos da história da fenomenologia, em Fenomenologia na Psicologia e na Psiquiatria (1972, no original Phenomenology in Psychology and Psychiatry), desqualifica Jung, enquanto fenomenólogo. Afirma que, ao utilizar o termo fenomenologia, Jung estava simplesmente apropriando-se de um recurso de linguagem que estava se popularizando à época.

Tal desencontro, entretanto, não significava um afastamento de Jung da própria filosofia, da qual era leitor assíduo. Sua relação com a disciplina filosófica foi descrita por Giegerich (2007) como marcada por "estranhas ambivalências". Podem-se constatar em seu trabalho declarações díspares sobre a questão. Em uma de suas cartas, Jung escreve: "Não sou filósofo, mas médico e empírico. Pratico a psicologia em primeiro lugar como ciência. Em segundo lugar, ela me serve como instrumento psicoterapêutico" (2002, p. 231). Em contrapartida, nas Obras Completas, afirma:

Nós, os psicoterapeutas, deveríamos ser filósofos, ou médicos-filósofos - não consigo deixar de pensar assim. Aliás, já o somos, em que pese admiti-lo, porque é grande demais a diferença entre o que nós exercemos e aquilo que é ensinado como Filosofia nas faculdades (2004, p. 76).

Dentre os autores que mais influenciaram seu pensamento, Kant se destaca como aquele cujo sistema melhor ofereceu recursos para Jung fundamentar sua psicologia. Jung compreende "fenômeno" em um sentido kantiano, ou seja, toma o fenômeno em contrapartida ao númeno, ou seja, aquilo que aparece em oposição às coisas em si mesmas. Além disso, Jung concorda com a idéia de Kant de que o númeno não é acessível ao conhecimento, de modo que toda ciência, para ser válida, precisa voltar-se para o campo dos fenômenos. Uma psicologia científica deve, por sua vez, ocupar-se de fenômenos psíquicos e não de metafísica. Em relação a essa questão, Xavier (2008) menciona que:

Jung frisava a importância de diferenciar as imagens arquetípicas dos arquétipos em si mesmos, as representações daquilo que as fomenta, e a concretabilidade daquilo que não podemos conceber. Em síntese, por detrás de qualquer imagem consciente há sempre um númeno inconsciente, inalcançável para nossa razão (...).

Para Jung, manter uma postura fenomenológica significava valorizar a experiência, compreendida como a experiência vivida pelo indivíduo. Tal posição era central à sua crítica à teorização freudiana. $\mathrm{O}$ apego de Freud à sua teoria sexual, bem como sua preocupação com a elaboração de um sistema metapsicológico coerente e fechado, o teria afastado de uma atitude inicialmente empírica e descritiva em direção à construção de uma ciência da interpretação.

Mas não podemos afirmar que o ponto de vista fenomenológico tenha penetrado em todas as mentes. A teoria ainda desempenha um papel demasiado importante em toda parte, em vez de ser incluída na fenomenologia, como deveria ser. Até mesmo Freud, cuja atitude empírica é incontestável, acoplou sua teoria como um sine qua non com o método, como se o fenômeno psíquico tivesse de ser inevitavelmente visto por um certo prisma para ter algum valor (Jung, 2003, p. 67).

Colocada em contraposição aos modelos explicativos que assumem um caráter metafísico em Psicologia, a proposta fenomenológica de Jung se reflete na sua concepção de ciência e de método científico de trabalho, que contempla a necessidade de se assumir uma postura semelhante ao "colocar entre parênteses" da redução fenomenológica husserliana:

A psicologia médica reconheceu que os fatos decisivos são extraordinariamente complexos e só podem ser apreendidos através da descrição casuística. Este método, porém, exige que se esteja livre de pressupostos teóricos. Toda ciência natural é descritiva quando não pode mais proceder experimentalmente, sem, no entanto, deixar de ser científica. Mas uma ciência experimental torna-se inviável quando delimita seu campo de trabalho segundo conceitos teóricos. A 
alma não termina lá onde termina um pressuposto fisiológico ou de outra natureza. Em outras palavras, em cada caso singular, cientificamente observado, devemos levar em consideração o fenômeno anímico em sua totalidade (Jung, 2003, p. 68).

O processo de observação do fenômeno não é, para Jung, algo independente da atividade cognoscitiva do sujeito. Todo o conhecimento, seja ele geral ou psicológico, é sempre co-determinado pela psique, ou seja, influenciado pelos fatores subjetivos e pelas equações pessoais. Em Tipos Psicológicos (1991), ele irá discutir como o fator subjetivo influi nos estímulos do objeto mundo.

O ideal e objetivo da ciência não consistem em dar uma descrição, a mais exata possível, dos fatos - a ciência não pode competir com a câmera fotográfica ou com o gravador de som - mas em estabelecer a lei que nada mais é do que a expressão abreviada de processos múltiplos que, no entanto, mantêm certa unidade. Este objetivo se sobrepõe, por intermédio da concepção, ao puramente empírico, mas será sempre, apesar da sua validade geral e comprovada, um produto da constelação psicológica subjetiva do pesquisador. $\mathrm{Na}$ elaboração de teorias e conceitos científicos há muita coisa de sorte pessoal. Há também uma equação pessoal psicológica e não apenas psicofísica. Enxergamos cores, mas não o comprimento das ondas. Esta realidade bem conhecida deve ser levada em conta na psicologia, mais do que em qualquer outro campo. $\mathrm{O}$ efeito dessa equação pessoal já começa na observação. Vemos aquilo que de melhor podemos ver a partir de nós mesmos (p. 25-26).

Percebe-se em Merleau-Ponty (1945/1994), que a teoria do conhecimento da Fenomenologia tem pontos de aproximação da de Jung:

Tudo aquilo que sei do mundo, mesmo por ciência, eu o sei a partir de uma visão minha ou de uma experiência do mundo sem a qual os símbolos da ciência não poderiam dizer nada. Todo o universo da ciência é construído sobre o mundo vivido, e se queremos pensar a própria ciência com rigor, apreciar exatamente seu sentido e seu alcance, precisamos primeiramente despertar essa experiência do mundo da qual ela é a expressão segunda (p. 3).

O mesmo autor postula, em trabalho posterior, que a compreensão do mundo vivido, que equivale à busca das essências,

(...) é obtida por 'livre variação’ imaginária de certos fatos. Para conseguir visar uma essência, consideramos uma experiência concreta e fazemo-la variar em pensamento, imaginamo-la efetivamente modificada sob todos os aspectos, de modo que, através destas modificações, aquilo que permanece inalterável é a essência dos fenômenos considerados (Merleau-Ponty, 1958/1973, p. 47).

Jung apresenta um objetivo análogo para a amplificação arquetípica, um instrumento central de sua prática psicoterapêutica, que visa distinguir a estrutura central do arquétipo a partir de suas infindáveis variações. Exemplifica:

É possível, por exemplo, que uma pessoa diga “água”. Será que eu sei o significado pessoal de água para essa pessoa? Absolutamente não. Se, num contexto, eu apresentar tal palavra a alguém, essa outra pessoa poderá dizer "verde". Uma outra, " $\mathrm{H}_{2} \mathrm{O}$ ”, o que seria completamente diferente. Haveria ainda novas, diria infinitas, possibilidades: "mercúrio", "suicídio”, etc. Em cada caso é possível descobrir a estrutura em que tais associações se inserem. Nisto consiste a amplificação, um procedimento lógico bem conhecido, aqui aplicado exatamente para formular a técnica de descobrir o contexto (2000, p. 97).

Outra característica da obra junguiana que se aproxima das propostas fenomenológicas é a sua concepção de alma que, em alguns momentos, é utilizada em um sentido próximo à de intencionalidade de Husserl. Disposto a encarar o fenômeno psicológico em seus próprios termos e respeitando a integridade da experiência, Jung compreende a Psicologia como uma "ciência intermediária, capaz de, só ela, conciliar idéia e objeto sem violentar nem um nem outro" (Jung, 1991, p. 60). O foco recai sobre o campo intermediário do homem consigo mesmo e com o mundo, apontando, na tentativa de solucionar o dilema mente-corpo, para um terceiro ponto de vista: esse in anima [ser na alma].

Ao esse in intellectu [ser na mente] falta a realidade tangível, e ao esse in re [ser no corpo] falta o espírito. Idéia e coisa confluem na psique humana que mantém o equilíbrio entre elas. Afinal o que seria da idéia se a psique não lhe conferisse um valor vivo? E o que seria da coisa objetiva se a psique lhe tirasse a força determinante e a impressão sensível? O que é a realidade se não for uma realidade em nós, um esse in anima? A realidade viva não é dada exclusivamente pelo produto do comportamento real e objetivo das coisas, nem pela formula ideal, mas pela combinação de ambos no processo psicológico vivo, um esse in anima (Jung, 1991, p. 63).

A Psicologia Analítica procura, então, reconstituir essa terceira instância, o reino intermediário da psique, que é, também, o reino das imagens e do poder da ima- 
ginação. Utilizando a atividade da fantasia "a psique cria realidade todos os dias" e "lança uma ponte entre sujeito e objeto" (Jung, 1991, p. 64).

A ênfase de Jung nos processos imagéticos coaduna-se com o caminho seguido por outros pensadores influenciados por Husserl. O francês Gaston Bachelard (18841962) postulou a imaginação como elo entre o homem e o mundo, competindo ao método fenomenológico "precisar o verdadeiro caráter da imagem em face da percepção" (Simões, 1999, p.54). Segundo Simões, "ambos, Jung e Bachelard, combatem o trabalho com as imagens que não levam a sério as imagens em si mesmas. (...) É preciso respeitar a realidade da própria imagem" (p. 54).

Essa argumentação evidencia a relevância da função criativa da psique, que raciocina imageticamente. Para Jung, o equivalente racional mais próximo à atividade psíquica é a analogia ou a metáfora. O foco terapêutico que se estabelece, por conseqüência, está na textura metafórica das coisas e imagens que produzem uma riqueza de insights psicológicos.

Momentos em que Jung se aproxima da fenomenologia não constituem, no entanto, a totalidade de seu pensamento. Brooke (2008) aponta que Jung é criticado por não ter questionado o pensamento cartesiano, suficientemente, a fundo, de modo que suas reflexões permanecem pautadas numa separação entre sujeito e objeto. Em sua Psicologia do conhecimento, ou seja, na teoria dos tipos e na teoria do símbolo, Jung, fiel a Kant, salienta a necessidade de se manter a distinção fundamental entre os "objetos da realidade", pelos quais ele se refere ao conjunto das coisas e processos que estão no mundo real e são externos e independentes do sujeito, e os "objetos do conhecimento", também chamados de objetos internos ou representações. Conceber um mundo independente da consciência não coaduna com o pensamento husserliano, especialmente no que diz respeito à radicalidade do conceito de intencionalidade. Além disso, o argumento subjetivista de Jung a favor da validade dos conteúdos psíquicos, severamente criticado, o isolou da comunidade científica e das comunidades filosófica e teológica (Nagy, 1991/2003, p. 46).

Outro ponto de fuga pode ser apontado na proximidade de Jung com as ciências naturais (Brooke, 2008). Jung era, por formação, médico psiquiatra. Enquanto tal, ele se expressou usando a linguagem da psicopatologia: esquizofrenia, dissociação da personalidade, projeção, etc. Por intermédio da Psiquiatria, Jung concebe a patologia como algo que se instala "dentro" do homem e, os processos de saúde e doença, concebe como reflexos da distribuição e disponibilidade energética independentes do observador. É desse lugar, por exemplo, que ele discorre sobre o psiquismo e os instintos:

Aliás, é forçoso admitirmos como provável que tudo aquilo que chamamos de psíquico está incluído na totalidade dos instintos e que, portanto, o psiquis- mo outra coisa não é, em última análise, senão um instinto ou conglomerado de instintos, ou seja, uma função hormonal (Jung, 1988, p. 331).

Cabe dizer, a favor da posição fenomenológica de Jung, que, conquanto ele se debatesse com temáticas pertinentes ao campo da medicina, ele tinha bem clara a "monstruosa complexidade" dos fenômenos biológicos e que noções tais como instinto "representam, no fundo, um $X$, isto é, pura e simplesmente um conceito-limite, cujo conteúdo é a imprecisão absoluta" (Jung, 1988, p. 331). Ainda que Jung nunca tenha abandonado por completo sua origem na psiquiatria e nos estudos de associações de palavras, ele se afasta dessa perspectiva, na medida em que amadurece. Em geral, sua compreensão dos fatos está muito mais próxima das ciências humanas ou das ciências do espírito (geistswissenchaften), como denominou Dilthey.

\section{Considerações Finais}

A aproximação entre Jung e Husserl não se dá em termos de radicais filosóficos. No âmbito dos conceitos, Jung permanece kantiano. Entretanto, a valorização da experiência inerente ao pensamento junguiano sugere uma postura semelhante a que a epoché produz nas psicologias fenomenológicas.

Brooke (no prelo) sintetiza tal aproximação, alinhando quatro conceitos fundamentais da fenomenologia a posições assumidas por Jung: (1) A descrição fenomenológica e a proposta junguiana de não distanciamento do fenômeno, tal como este ocorre; (2) a redução fenomenológica e a insistência de Jung em manter sua discussão dentro do campo psicológico, sem adentrar uma metafísica; (3) a busca das essências e a amplificação arquetípica; (4) a intencionalidade e a compreensão de Jung de que a relação do homem com o mundo é inerentemente permeada pela alma e pelo corpo, este compreendido como materialidade daquela.

A obra de Jung, tanto no que tem de inovadora, quanto em suas obscuridades filosóficas, precisa ser compreendida em sua historicidade. Tomar de empréstimo idéias da Fenomenologia pode vir a ser um caminho promissor para que se possa entender seu sentido, hoje. Além disso, a proximidade acadêmica entre a Psicologia Analítica e as psicologias fenomenológicas, não só é justificável epistemologicamente, como pode ser fecunda para ambas as partes. Isso tem sido confirmado, por exemplo, com os rumos tomados pela Psicologia Arquetípica.

\section{Referências}

Bello, A. A. (2004). Fenomenologia e Ciências Humanas. (M. Mahfoud \& M. Massini, Trads.) Bauru: EDUSC. 
Bonaccini, J. A. (2006). O conceito hegeliano de "Fenomenologia" e o problema do ceticismo. Veritas, 51(1), 56-68.

Brooke, R. (2008). Jung and Phenomenology. Pittsburgh: Trivium Publications.

Brooke, R. (no prelo) Jung and Phenomenology. Em D. Leeming, K. Madden, \& S. Marlan (Orgs.), Encyclopedia of Psychology and Religion. Springer.

Clarke, J. J. (1993). Em busca de Jung: indagações históricas e filosóficas. (R. Jungmann, Trad.) Rio de Janeiro: Ediouro. (Originalmente publicado em 1992).

Dartigues, A. (2008). O que é Fenomenologia? São Paulo: Centauro.

Ellenberger, H. (1970). The Discovery of the Unconscious: the History and Evolution of Dynamic Psychiatry. New York: Basic Books Inc.

Forghieri, Y. C. (1993). Psicologia Fenomenológica: fundamentos, método e pesquisas. São Paulo: Pioneira.

Giegerich, W. (2004). The end of meaning and the birth of man. Journal of jungian theory and practice, 6 (1), 1-23.

Giegerich, W. (2007). Psychology as anti-philosophy: C. G. Jung. Spring Journal, 77, 11-51.

Hamlyn, D. W. (1990). Uma breve história da filosofia ocidental. (R. Jungmann, Trad.) Rio de Janeiro: Zahar. (Originalmente publicado em 1987).

Hillman, J. (1992). Psicologia Arquetípica. (L. Rosenberg \& G. Barcellos, Trads.) São Paulo: Cultrix. (Originalmente publicado em 1988).

Jung, C. G. (1991). Tipos psicológicos. Obras Completas, vol. VI. Petrópolis: Vozes.

Jung, C. G. (1988). A psicologia da religião ocidental e oriental. Obras Completas, vol. XI. Petrópolis: Vozes.

Jung, C. G. (2000). A vida simbólica. Obras Completas, vol. XVIII/1. Petrópolis: Vozes.

Jung, C. G. (2001). Cartas: 1906-1945. Obras Completas, vol. I. Petrópolis: Vozes.

Jung, C. G. (2002). Cartas: 1946-1955. Obras Completas, vol. II. Petrópolis: Vozes.

Jung, C. G. (2003). Os arquétipos do inconsciente coletivo. Obras Completas, vol. IX. Petrópolis, Vozes.

Jung, C. G. (2004). A prática da psicoterapia. Obras Completas, vol. XVI/1. Petrópolis, Vozes.

Maciel, J. de C. (2007). Franz Clemens Brentano e a Psicologia. Em M. A. de T. Bruns \& A. F. Holanda (Orgs.), Psicologia e Fenomenologia: Reflexões e Perspectivas (pp. 27-40). Campinas: Alínea.

Merleau-Ponty, M. (1973). Ciências do Homem e Fenomenologia. (S. T. Muchail, Trad.) São Paulo: Martins Fontes. (Originalmente publicado em 1958).
Merleau-Ponty, M. (1994). Fenomenologia da percepção (C. Moura, Trad.). São Paulo: Martins Fontes. (Originalmente publicado em 1945).

Nagy, M. (2003). Questões filosóficas na psicologia de C. G. Jung. (A. M. Spira, Trad.) Petrópolis: Vozes. (Originalmente publicado em 1991).

Reale, G. \& Antiseri, D. (2005a). História da Filosofia: de Spinoza a Kant. vol. 4. São Paulo: Paulus.

Reale, G., \& Antiseri, D. (2005b). História da Filosofia: do Romantismo ao Empiriocriticismo. vol. 5. São Paulo: Paulus.

Shamdasani, S. (2006). Jung e a Construção da Psicologia Moderna. (M. S. M. Netto, Trad.) São Paulo: Idéias e Letras. (Originalmente publicado em 2003).

Simões, R. L. M. (1999). A Imaginação Material Segundo Gaston Bachelard. Dissertação de Mestrado, Universidade do Estado do Rio de Janeiro, Rio de Janeiro.

Spiegelberg, H. (1972). Phenomenology in Psychology and Psychiatry. Evanston: Northwestern University Press.

Xavier, C. R. (2008). Diálogo do Imponderável: cinco ensaios sobre o objeto psicológico a partir da filosofia da mente. Tese de Doutorado, Universidade Federal de São Carlos, São Carlos.

Von Franz, M. L.; (1992). C. G. Jung: seu mito em nossa época. (A. U. Sobral, Trad.) São Paulo: Cultrix. (Originalmente publicado em 1975).

Zilles, U. (2007) Fenomenologia e teoria do conhecimento em Husserl. Revista da Abordagem Gestáltica. 13 (2), 216-221.

Andrea de Alvarenga Lima - Graduada em História pela Universidade Federal do Paraná, Especialista em Psicologia Analítica, além de ser graduanda em Psicologia e Mestranda pelo Programa de Pós-Graduação em Psicologia da Universidade Federal do Paraná. Email: andrealima@ufpr.br

Jean Carlo Kurpel Diogo - Graduando de Psicologia na Universidade Federal do Paraná. Email: jean.diogo@yahoo.com.br

Recebido em 12.05.09 Aceito em 23.07.09 